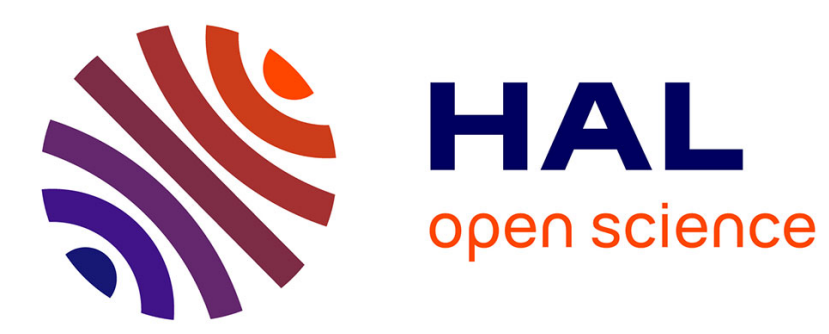

\title{
Anomalous conductivity in PZT thin film deposited on copper substrate electrode
}

\author{
Andrei Th Ionescu, Anca-Luiza Alexe-Ionescu, Salvatore Marino, Marco \\ Castriota, Giuseppe Strangi, Gaetano Nicastro, Nicola Scaramuzza
}

\section{To cite this version:}

Andrei Th Ionescu, Anca-Luiza Alexe-Ionescu, Salvatore Marino, Marco Castriota, Giuseppe Strangi, et al.. Anomalous conductivity in PZT thin film deposited on copper substrate electrode. Philosophical Magazine, 2010, 90 (13), pp.1733-1742. 10.1080/14786430903463529 . hal-00587294

\section{HAL Id: hal-00587294 https://hal.science/hal-00587294}

Submitted on 20 Apr 2011

HAL is a multi-disciplinary open access archive for the deposit and dissemination of scientific research documents, whether they are published or not. The documents may come from teaching and research institutions in France or abroad, or from public or private research centers.
L'archive ouverte pluridisciplinaire HAL, est destinée au dépôt et à la diffusion de documents scientifiques de niveau recherche, publiés ou non, émanant des établissements d'enseignement et de recherche français ou étrangers, des laboratoires publics ou privés. 


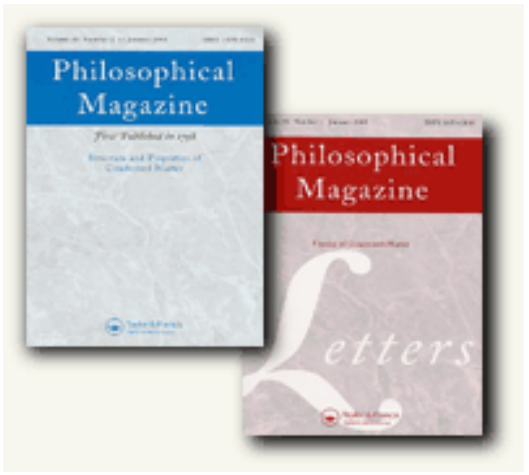

\section{Anomalous conductivity in PZT thin film deposited on copper substrate electrode}

\begin{tabular}{|c|c|}
\hline Journal: & Philosophical Magazine \& Philosophical Magazine Letters \\
\hline Manuscript ID: & TPHM-09-Jul-0293.R1 \\
\hline Journal Selection: & Philosophical Magazine \\
\hline $\begin{array}{r}\text { Date Submitted by the } \\
\text { Author: }\end{array}$ & $16-$ Oct-2009 \\
\hline Complete List of Authors: & $\begin{array}{l}\text { Ionescu, Andrei; Universitatea din Bucuresti, Facultatea de Fizica } \\
\text { Alexe-Ionescu, Anca-Luiza; Universitatea "Politehnica" din } \\
\text { Bucuresti, Departamentul de Fizica } \\
\text { marino, salvatore; University of Calabria, department of physics } \\
\text { castriota, marco; University of Calabria, department of physics } \\
\text { strangi, giuseppe; University of Calabria, department of physics } \\
\text { nicastro, gaetano; University of Calabria, department of physics } \\
\text { Scaramuzza, Nicola; University of Calabria, department of physics }\end{array}$ \\
\hline Keywords: & ferroelectrics, copper, electrical conductivity, films, interfaces \\
\hline Keywords (user supplied): & \\
\hline
\end{tabular}

\section{(5) ScholaroNE \\ Manuscript Central}




\title{
Anomalous conductivity in PZT thin film deposited on copper substrate electrode.
}

\author{
Andrei Th. Ionescu ${ }^{\mathrm{a}}$, Anca-Luiza Alexe-Ionescu ${ }^{\mathrm{b}}$, Salvatore Marino ${ }^{\mathrm{c}}$, Marco \\ Castriota $^{\mathrm{c}}$, Giuseppe Strangi ${ }^{\mathrm{c}}$, Gaetano Nicastro ${ }^{\mathrm{c}}$ and Nicola Scaramuzza ${ }^{\mathrm{c}, *}$
}

a) Facultatea de Fizica, Universitatea din Bucuresti, P.O.B MG-11, Ro-077125 Bucharest, Romania

b) Departamentul de Fizica, Universitatea "Politehnica' din Bucuresti, Splaiul Independentei 313, Ro-060042 Bucharest, Romania

c) INFM-CNR-LICRYL Laboratory-CEMIF.CAL, Department of Physics University of Calabria, Via P. Bucci, Cubo 33B, 87036 Rende (CS) Italy

*) Corresponding author. Tel.: (+39) 0984-496113 Fax. (+39) 0984-494401 E-mail: scaramuzza@fis.unical.it 


\begin{abstract}
Electrical properties of ferroelectric films are influenced by many factors among which the methods of synthesizing the ferroelectric film itself and the characteristics of the substrate electrode. Conductivity measurements were performed on PZT (lead zirconate titanate) thin films deposited by sol-gel synthesis on a copper electrode aiming to investigate the electric properties and to individuate the predominant charge carriers of such samples. A semiconducting $\mathrm{PZT} / \mathrm{Cu}$ interface appears during the thermal treatment influencing severely the electric conduction. A power law, describing the transport mechanism across PZT film, has been found empirically.
\end{abstract}




\section{Introduction}

Thin films of lead zirconate titanate are of great scientific and technological interest, especially during the last decade, because of their application in non volatile memories, sensors and, more recently, in asymmetric nematic liquid crystal cells [13]. Moreover, the problems associated with the applications of ferroelectrics such as: polarization fatigue, field and frequency dependence of the piezoelectrics, elastic and dielectric properties, have produced an intensive research on the fundamental properties of ferroelectric materials.

One of the main aspects in understanding the behaviour of ferroelectric films is the interaction with the substrate material used as electrode. Platinum is the most popular substrate for ferroelectric materials because of its good resistance to oxidation. Otherwise, conducting oxide electrodes such as $\mathrm{RuO}_{2}[4], \mathrm{IrO}_{2}[5]$ or ITO[6] have been widely used.

In the present work a $\left[\mathrm{Pb}\left(\mathrm{Zr}_{0.53} \mathrm{Ti}_{0.47}\right) \mathrm{O}_{3}\right]$ (PZT) thin film obtained by sol-gel procedure has been deposited on a copper electrode by spin coating and, subsequently, submitted to annealing at $600^{\circ} \mathrm{C}$ for $1 \mathrm{~h}$ to ensure the transition to the ferroelectric perovskite phase. Interesting hypotheses about the sign and the mobility of the charge carriers have been drawn from the electrical measurements done upon this sample.

\section{Experimental Details}

Lead Zirconate Titanate (PZT) thin films were obtained by hybrid (carboxylate and alkoxides) sol-gel route and by spin coating deposition of the obtained mother 
solution on a copper substrate. The reagents used, supplied by Sigma-Aldrich, are: Lead(II) acetate trihydrate ( $99.999 \%$ ), Zirconium(IV) propoxide solution (70 wt. \% in 1-propanol), Titanium(IV) isopropoxide ( $99.999 \%$ ), Acetic acid glacial (99.99+ $\%)$, n-Propanol anhydrous (99.7\%), Ethylene glycol anhydrous (99.8\%).

The synthesis of the mother solution has been performed in "humidity free" Glove Box in Argon atmosphere (concentration of humidity and of molecular oxygen lower than $1 \mathrm{ppm})$. Briefly, in order to obtain stable mother solution, $10.43 \mathrm{~g}$ of $\mathrm{Pb}(\mathrm{CH} 3 \mathrm{COO}) 2 \cdot 3 \mathrm{H} 2 \mathrm{O}$ have been dissolved in $\mathrm{CH} 3 \mathrm{COOH}$. The amount of acetic acid was chosen to have its mole number twice the sum of the mole number of lead, zirconium, and titanium. When the Lead(II) acetate trihydrate is completely dissolved, stoichiometric amounts of $\mathrm{Zr}(\mathrm{C} 3 \mathrm{H} 7 \mathrm{O}) 4$ and $\mathrm{Ti}[(\mathrm{CH} 3) 2 \mathrm{CHO}] 4$ solutions have been added, taking care to the temperature of the solution. Finally, when the solution is cooled down at room temperature, acetic acid, n-propanol (23.10 g) and ethylene glycol (1.16 g) have been added and the resulting solution is left to stir for one night. The amount of acetic acid used, at this step, was calculated as the total mole number of the acetic acid present in solution equal to 25 times the titanium mole number.

Bi-distilled water $(9 \mathrm{ml})$ has been added to the solution before the deposition on the different substrates. The details of the synthesis can be found elsewhere [3]. To obtain thin films, a spin coater, supplied by CaLCTec s.r.l. Model SC10, has been used. Later on, the films were subjected, for one hour, to a single thermal treatment in an oven, under ambient atmosphere, at $600^{\circ} \mathrm{C}$, with a ramp rate of $25^{\circ} \mathrm{C} / \mathrm{min}$. The thickness of the films thus obtained was about $1 \mu \mathrm{m}$. 
Images and microanalyses of PZT powders were made using a Quanta FEG 400 electronic microscope (Fei, The Netherlands). Such PZT powder has been obtained by scratching the exterior surface of PZT film deposited on the copper layer, so that to avoid the influence of copper substrate on the measurement. In Fig.1 we report: (a) a picture of the powder spread on the carbon stab of the SEM; (b) a magnification of the area on which the microanalyses has been effected and (c) the related microanalyses. The presence of copper inside the PZT is clearly confirmed by the line detected at $8 \mathrm{keV}$ and $1 \mathrm{keV}$, while $\mathrm{Zr}, \mathrm{Pb}$ and $\mathrm{Ti}$ are visible at $2 \mathrm{keV}, 2.4 \mathrm{keV}$ and $10.5 \mathrm{keV}$ and $4.5 \mathrm{keV}$, respectively. The migration of copper ions inside the PZT film plays an important role on the electric transport properties of the film, to be presented later. From Fig.1b one can also estimate the roughness of the film $\sim 0.5 \mu \mathrm{m}$.

To measure and investigate the current flow through the PZT film we have used the setup shown in Fig.2. The copper substrate (henceforth called the copper bottom electrode) is connected to the output of a voltage source (Wavetek Universal Waveform Generator model 195). The signal applied to the electrode was a triangular wave with a wide range of frequencies running from $2.5 \mathrm{mHz}$ to $500 \mathrm{~Hz}$ in four steps per decade, but with the same voltage amplitude (10V peak to peak). The upper electrode was a copper cube $(1 \mathrm{~cm}$ edge) placed with one of its optically polished bases directly in contact to the PZT film (the contact pressure was provided by the very weight of the copper cube). We have made this choice on purpose lest introduce a contact voltage between two different materials electrodes. This electrode is connected to the ground by a rather small and well known resistor $(100 \Omega)$. The voltages drop on this resistor, measured and recorded by a high input impedance 
oscilloscope (Agilent Infiniium 54832D MSO), is directly proportional to the electric current through the PZT film. To minimize the noise, the measuring setup (substrate, PZT film, upper electrode, and the measuring resistor) was surrounded by a grounded Faraday cage (not shown in the figure). Another channel of the oscilloscope was used to visualize and record the applied triangular wave, this last one also serving to trigger the oscilloscope. For each frequency two sets of data have been recorded, allowing representing currents and voltages versus time, or currents versus applied voltage. The digitized sets of data are amenable to several kind of mathematical processing (for instance: peak area integration, smoothing, curve fitting, etc.). All the measurements have been performed at room temperature.

\section{Results}

The measurements done at $2.5 \mathrm{mHz}$ and $500 \mathrm{~Hz}$ are showed in Fig.3 where the triangular applied voltage (thin line) and the current flowing trough the sample (full dots) are visible. Two remarkable features can be noticed: i) the strong frequency dependence of the current flowing through the PZT film; in fact the current measured at $2.5 \mathrm{mHz}$ (Fig. $3 a$ ) is sensibly greater than the current measured at $500 \mathrm{~Hz}$ (Fig.3b); ii) the semiconductor behaviour of this system, in fact the current flowing through the PZT film is almost cut for the negative polarity of the applied voltage. Also in Fig. $3 b$ one can see the displacement shift in measured current due to the fact that the applied voltage varies linearly in time giving birth to a constant current proportional to the capacitance of the sample and to the rate of the triangular signal. For a $2.5 \mathrm{mHz}$ applied voltage this displacement shift is practically equal to zero, hardly to be seen 
in Fig.3a. Subtracting or adding half of this shift, one can get rid of the displacement current and remain only with the conduction current. By plotting this conduction current versus the applied voltage (Fig.4) we obtain a diode like curve in which a hysteresis on the positive side of the graphic is clearly seen.

A first conclusion can be drawn at this stage, namely, the electric conduction through PZT is mainly ionic. At least two facts justify the previous assertion: if the current were electronic there should not have been any difference in the measured currents for $2.5 \mathrm{mHz}$, or $10 \mathrm{mHz}, 25 \mathrm{mHz}$, etc., the electronic mobilities being quite large in normal electronic conductors. Another fact might be drawn by inspecting the aforementioned displacement shift: let

$\left|\Delta i_{d i s p l}\right|=2 \frac{d Q}{d t}=2 C \frac{d V}{d t}$

Knowing $\frac{d V}{d t}$ (for instance $\frac{d V}{d t}=10^{4} \frac{V}{s}$ for $500 \mathrm{~Hz}$ and $10 \mathrm{~V}_{\mathrm{pp}}$ ) and measuring $\left|\Delta i_{\text {displ }}\right|\left(170 \mu \mathrm{A}\right.$ from Fig.3b) the capacitance $C$ is estimated to be $C=1.7 \times 10^{-8} \mathrm{~F}$ and the relative permittivity is about 7 , typical for a solid dielectric (ferroelectric).

To obtain more information about the accumulating charge process that is responsible to the hysteresis, the positive increasing side (one quarter of the period) has been analyzed separately for each frequency and all of these plots have been fitted with the equation

$I(T, V)=a+b V^{m}$ 
connecting the current intensity $I$ to the period $T$ by means of the parameter $b$ ( $a$ gives just a shift of zero and it is not interesting), and to the applied voltage $V$, while $m$ is a constant. For all the plots a very good agreement with the experimental curve has been obtained. In Fig. 5 ( $a$ and $b$ ) the $I-V$ plots (black dots) for the lowest frequency value of the applied voltage $(2.5 \mathrm{mHz})$ and for a higher one $(250 \mathrm{~Hz})$ both fitted with the equation 1 (white continuous line) are reported, respectively. To get the relation between $b$ and $T$ the fitted values of the parameter $b$ have been plotted with respect to $T$ (see Fig.6) and a good simple fitting function has been found

$$
b(T)=\alpha+\beta T^{\gamma}
$$

where $\alpha=4.7510^{-8}, \beta=2.6010^{-8}, \gamma=0.25$. Using the equation (1) it is possible to find the displaced charge $Q$

$$
Q=\int_{0}^{T / 4} I d t=\frac{1}{V} \int_{0}^{V_{0}}\left(a+b V^{m}\right) d V=\frac{T}{4 V_{0}}\left(a V_{0}+\frac{b}{m} V_{0}^{m+1}\right)=\left(\frac{a}{4}+\frac{b V_{0}{ }^{m}}{4 m}\right) T
$$

where we used the fact that for the triangular voltage one has $V(t)=v t, d t=\frac{1}{v} d V$. As for $t=T / 4 \Rightarrow V=V_{0}$, we have $\frac{1}{v}=\frac{T}{4 V_{0}}, V_{0}$ being the amplitude of the triangular signal.

Now, using the equation (2) one gets 
$Q=\frac{T}{4}\left(a+\left(\alpha+\beta T^{\gamma}\right) \frac{V_{0}{ }^{m}}{m}\right)=p T+q T^{\gamma+1}$

where $p \equiv \frac{a}{4}+\frac{\alpha V_{0}{ }^{m}}{m}$ and $q \equiv \frac{\beta V_{0}{ }^{m}}{m}$.

Of course, the values $p$ and $q$ computed with $a, \alpha, \beta, m, V_{0}$ should be consistent only with the charge displaced during a quarter of a period, not with the accumulated hysteresis charge, but the order of magnitude should be the same. Finally we have been conducted to use the fitting function

$$
Q=p T+q T^{1.25}
$$

to fit the plot of the accumulated charge in function of the period (that is the included area of the hysteresis calculated for different values of the applied voltage frequency yielding an excellent agreement (see Fig.7).

\section{Discussion and conclusions}

The constant $m$ in $\operatorname{Eq}(1)$ turned out to be $m \approx \frac{7}{3}$. As a matter of fact $V^{m}$ dependence of $I$ is not unusual in physics. (The simplest example being Ohm's law where $m$ is, of course, 1).In our case $V^{\frac{7}{3}}$ law should be a consequence of the transport mechanism across the PZT film. The parameter $b$ is linked to the carrier density and it should depend on the liberation of new carriers, in time. As already argued, these carriers should have low mobility, i.e. they are ions, presumably $C u^{+}$or $C u^{2+}$, as the 
microanalyses clearly show (Fig.1c). The liberation and the re-absorption of carriers are slow processes, connected also to the internal electric field.

For each value of the voltage across the sample should be a characteristic time for free carriers to reach the new equilibrium value. If the sweeping time (that is $T / 4$ ) of the voltage is smaller than the characteristic time, the carrier concentration does not reach saturation. Contrary, decreasing the voltage (the next $1 / 4$ of a period) the accumulated charge carriers do not have enough time to diminish toward the equilibrium value, so the decreasing of the current does not follow the same path as the increasing current and this asymmetry creates the hysteresis charge. A rather large value of $\mathrm{m}$ indicated a thermal activated 3D hopping process [7].

The rectifying effect is closely connected to the large number of copper ions dissolved in the PZT side of the interface during the thermal treatment (see Fig.1c, again).

A sketch of the process is presented in Fig.8 and Fig.9. The absorbed copper ions form a positive layer within PZT right at the interface, while a negative charge (electrons) appears in the copper base interface to make the sample electrically neutral. A positive voltage on the copper base withdraws electrons from the compensating layer leaving the positive copper ions to diffuse into the bulk. So the concentration of positive charge on the opposite side of PZT increases thus attracting electrons from the ground across the measuring resistor. A negative voltage on the copper base narrows the positive ionic distribution in PZT stabilizing it and no positive charge is injected to the opposite side of PZT to produce a measurable 
current across the resistor. To be sure the positive copper ions diffusion into the bulk is a very slow process, thus accounting for the frequency dependence of the current.

Also, for practical purposes this small, but not at all negligible solubility of the substrate into the PZT layer should be taken into account. 


\section{References}

[1] C.T. Lin, B.W. Scanlan, J.D. McNeill, J.S. Webb, Li Li, R.A. Lipeles, P.M. Adams, M.S. Leung: Crystallization behavior in a low temperature acetate process for perovskite $\mathrm{PbTiO} 3, \mathrm{~Pb}(\mathrm{Zr}, \mathrm{Ti}) \mathrm{O} 3$, and (Pb1-x, Lax) (Zry, Ti1-y)1-x/4O3 bulk powders. J. Mater. Res. 7(9), 2546 (1992).

[2] S. S. Dana, K. F. Etzold, and J. Clabes: Crystallization of sol-gel derived lead zirconate titanate thin films. J. Appl. Phys 69(8), 4398 (1991).

[3] S. Marino, M. Castriota, G. Strangi, E. Cazzanelli, N. Scaramuzza: Asymmetric nematic liquid crystal cells containing lead zirconium titanate PZT films: Journal of Applied Physics. 102013112 (2007). Selected for Virtual Journal of Nanoscale Science \& Technology July 30, 2007.

[4] Gouji Asano, Hitoshi Morioka, Hiroshi Funakubo, Tetsuo Shibutami, and Noriaki Oshima: Fatigue-free $\mathrm{RuO} 2 / \mathrm{Pb}(\mathrm{Zr}, \mathrm{Ti}) \mathrm{O} 3 / \mathrm{RuO} 2$ capacitor prepared by metalorganic chemical vapor deposition at $395^{\circ} \mathrm{C}$. Appl. Phys. Lett. 83, 1512 (2003).

[5] B. S. Kang, D. J. Kim, J. Y. Jo, T. W. Noh, Jong-Gul Yoon, T. K. Song, Y. K. Lee, J. K. Lee, S. Shin, and Y. S. Park: Polarization retention in $\mathrm{Pb}(\mathrm{Zr} 0.4 \mathrm{Ti0.6}) \mathrm{O} 3$ capacitors with IrO2 top electrodes. Appl. Phys. Lett 84, 3127 (2004).

[6] E. Bruno, M.P. De Santo, M. Castriota, S. Marino, G. Strangi, E. Cazzanelli, and N. Scaramuzza: Morphological and electrical investigations of lead zirconium titanate thin films obtained by sol-gel synthesis on indium tin oxide electrodes. Journal of Applied Physics. 103, 064103 (2008).

[7] N.F. Mott, E.A. Davis, Electronic Processes in Non Crystalline Materials, $2^{\text {nd }}$ edn. (Oxford: Clarendon, 1979). 


\section{Figure captions}

Figure 1: Picture of PZT powder spread on the SEM carbon stab (a), magnification of the small square area shown in (a) and the related microanalyses (c).

Figure 2: Experimental setup; $\mathrm{r}$ - the measuring resistor $(100 \Omega)$.

Figure 3: The current through the PZT/copper sample when a triangular wave is applied. The frequency of the applied voltage: (a) $2.5 \mathrm{mHz}$; (b): $500 \mathrm{~Hz}$.

Figure 4: A typical current - voltage plot showing the hysteresis for positive voltages and rectification for negative voltages.

Figure 5: Current - voltage plots of the increasing ramp of the applied voltage at $2.5 \mathrm{mHz}(a)$ and $250 \mathrm{~Hz}(b)$. The black dots are the eperimental points and the white line is the fitting curve.

Figure 6: The plot of parameter $b$ versus period $T$. The open squares are the experimental points and the black line is the fitting curve.

Figure 7: Charge in function of period. The open squares are the experimental points and the black line is the fitting curve. 
Figure 8: (a) Equilibrium distribution of copper ions in PZT and the counter electrons in the copper base electrode; (b) copper base electrode under positive voltage; (c) copper base electrode under negative voltage.

Figure 9: Densities of charge carriers at copper base, PZT, and colecting copper electrode: (a) no voltage; (b) pozitive voltage; (c) negative voltage, as before. 

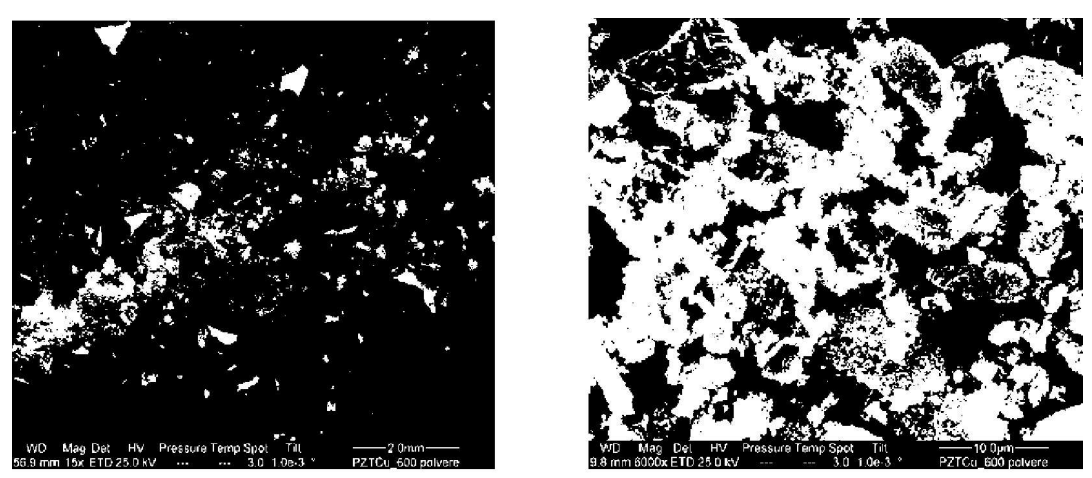

a)

b)

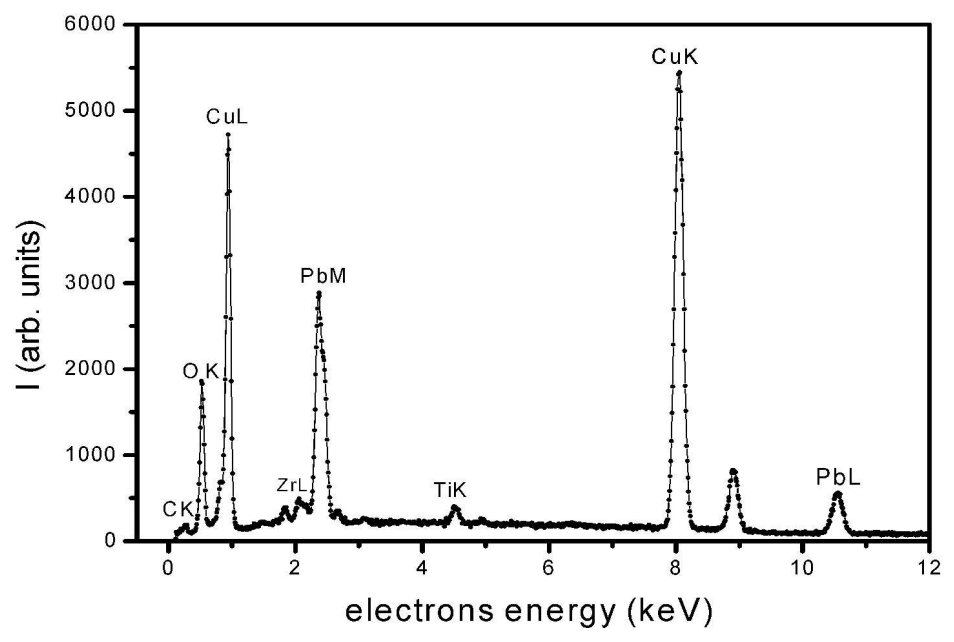

c)

FIGURE 1

$168 \times 246 \mathrm{~mm}(500 \times 500 \mathrm{DPI})$ 


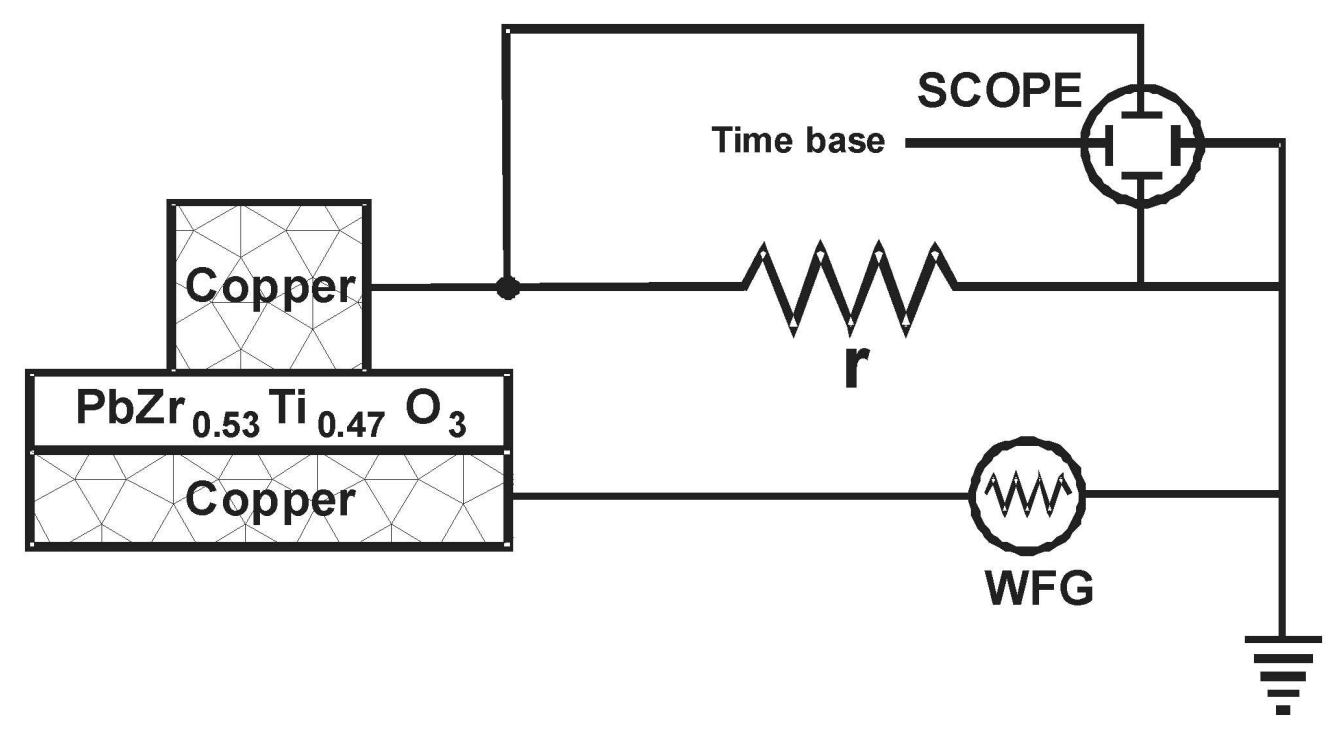

FIGURE 2

$169 \times 115 \mathrm{~mm}(300 \times 300 \mathrm{DPI})$ 


1
2
3
4
5
6
7
8
9
10
11
12
13
14
15
16
17
18
19
20
21
22
23
24
25
26
27
28
29
30
31
32
33
34
35
36
37
38
39
40
41
42
43
44
45
46
47
48
49
50
51
52
53
54
55
56
57
58
60

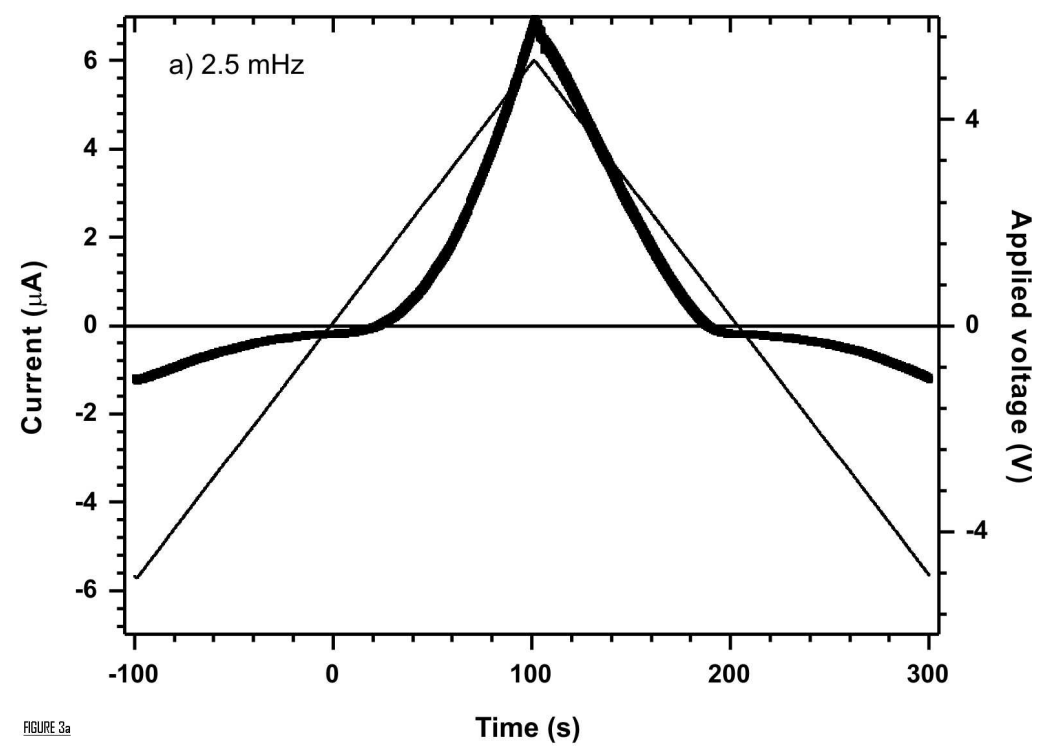

414x638mm (96 x 96 DPI) 


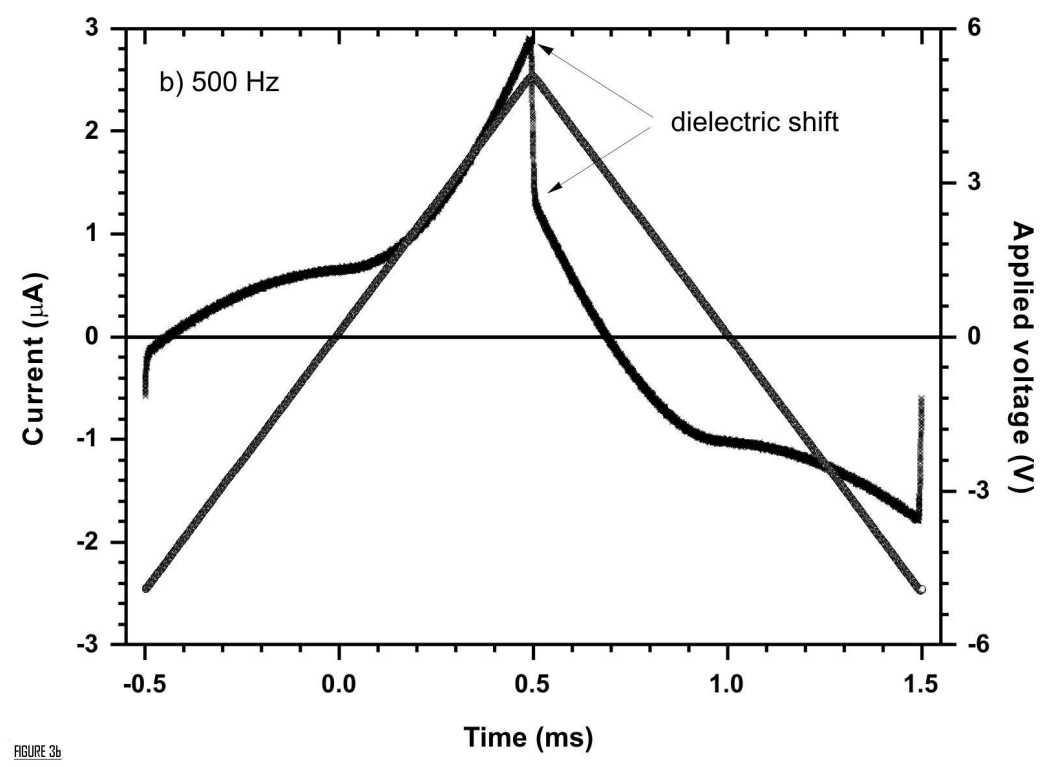

$420 \times 639 \mathrm{~mm}(96 \times 96 \mathrm{DPI})$ 
Page 19 of 25

Philosophical Magazine \& Philosophical Magazine Letters

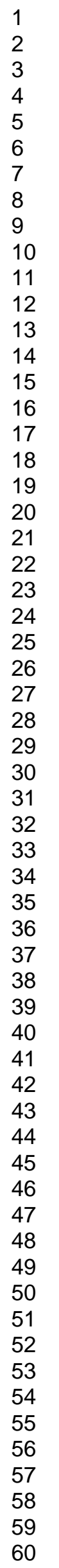

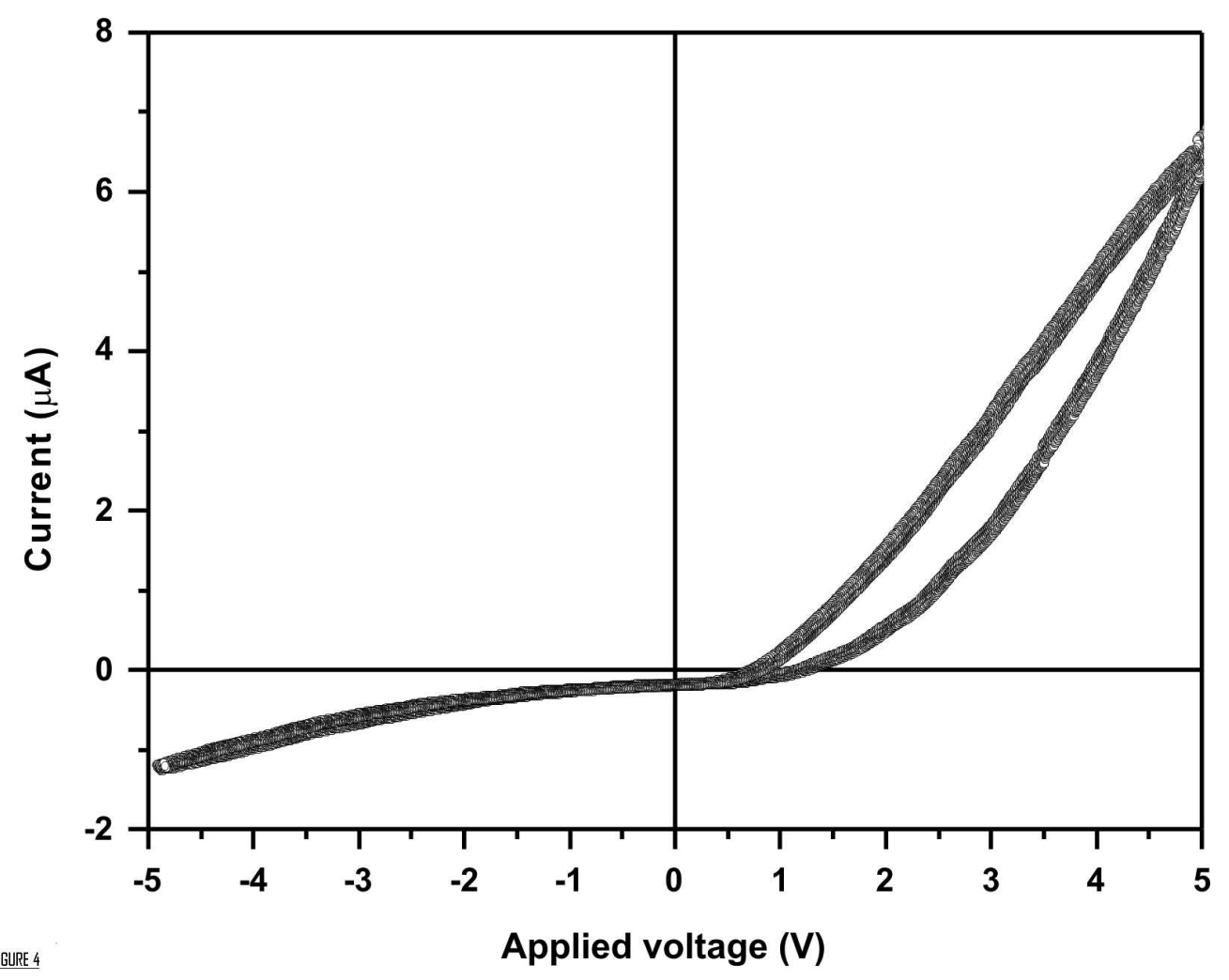

$433 \times 340 \mathrm{~mm}(96 \times 96 \mathrm{DPI})$

http://mc.manuscriptcentral.com/pm-pml 


1
2
3
4
5
6
7
8
9
10
11
12
13
14
15
16
17
18
19
20
21
22
23
24
25
26
27
28
29
30
31
32
33
34
35
36
37
38
39
40
41
42
43
44
45
46
47
48
49
50
51
52
53
54
55
56
50

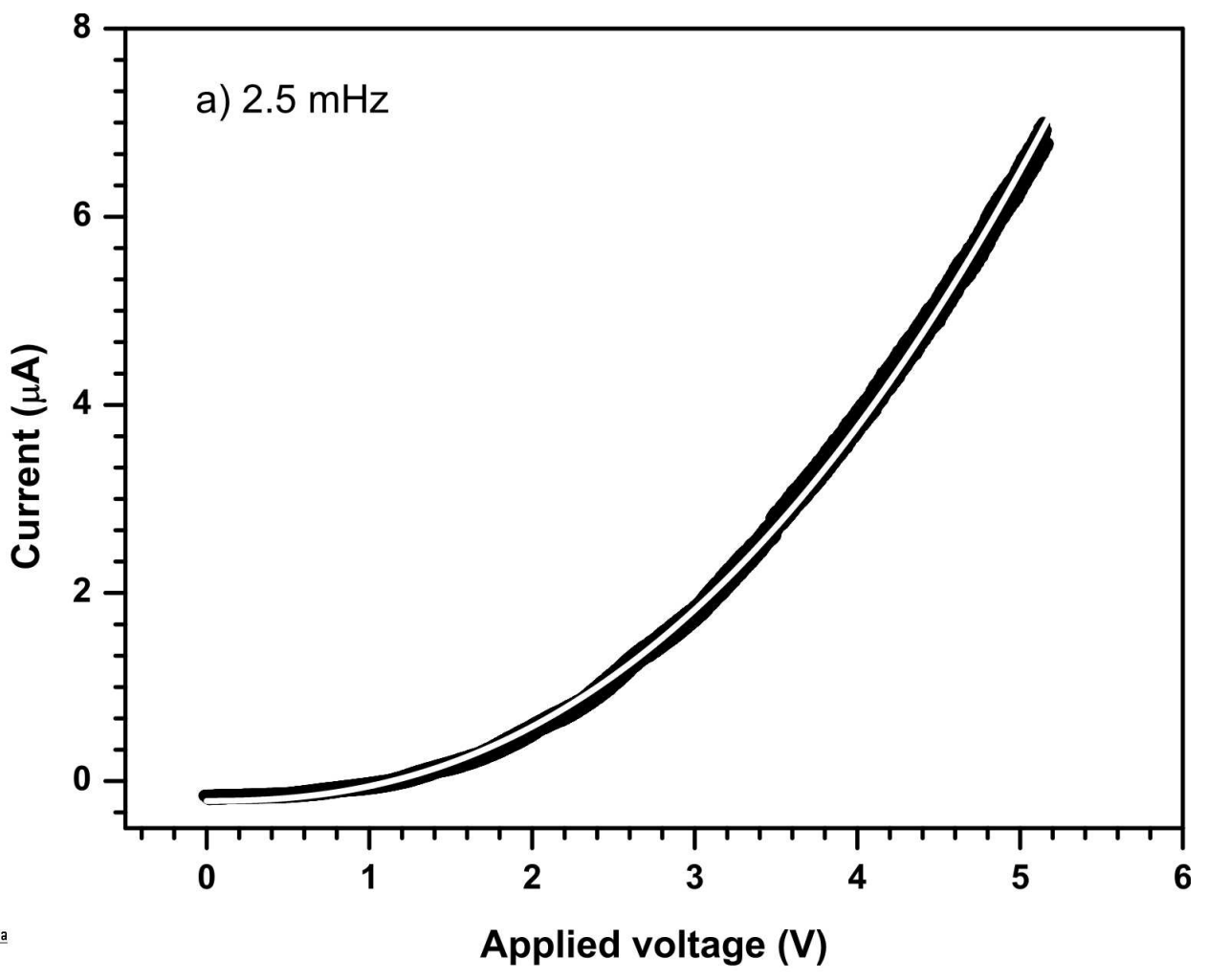

$429 \times 333 \mathrm{~mm}(96 \times 96 \mathrm{DPI})$ 
Page 21 of 25

Philosophical Magazine \& Philosophical Magazine Letters

1
2
3
4
5
6
7
8
9
10
11
12
13
14
15
16
17
18
19
20
21
22
23
24
25
26
27
28
29
30
31
32
33
34
35
36
37
38
39
40
41
42
43
44
45
46
47
48
49
50
51
52
53
54
55
56
58
59
60

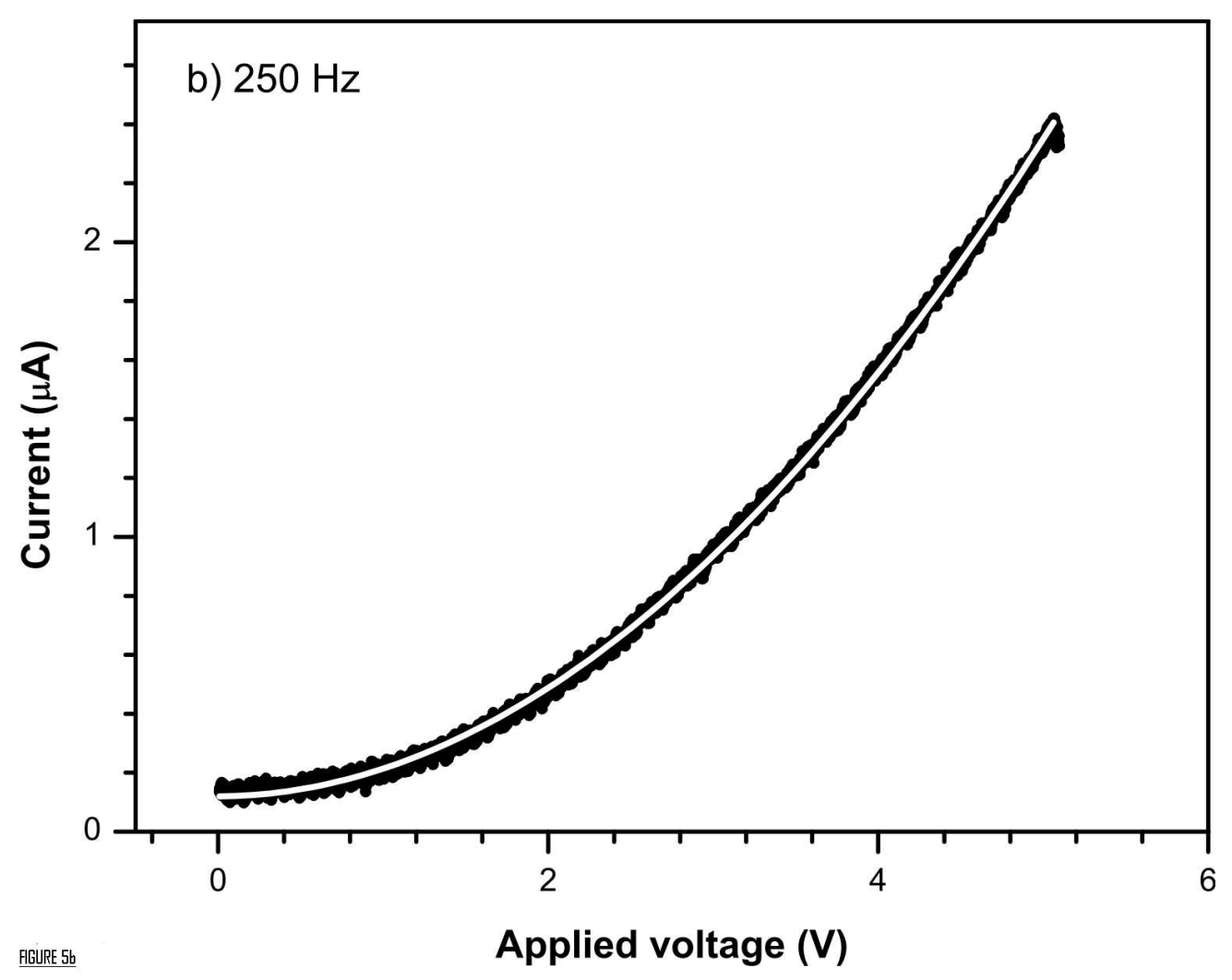

$408 \times 326 \mathrm{~mm}(96 \times 96 \mathrm{DPI})$

http://mc.manuscriptcentral.com/pm-pml 


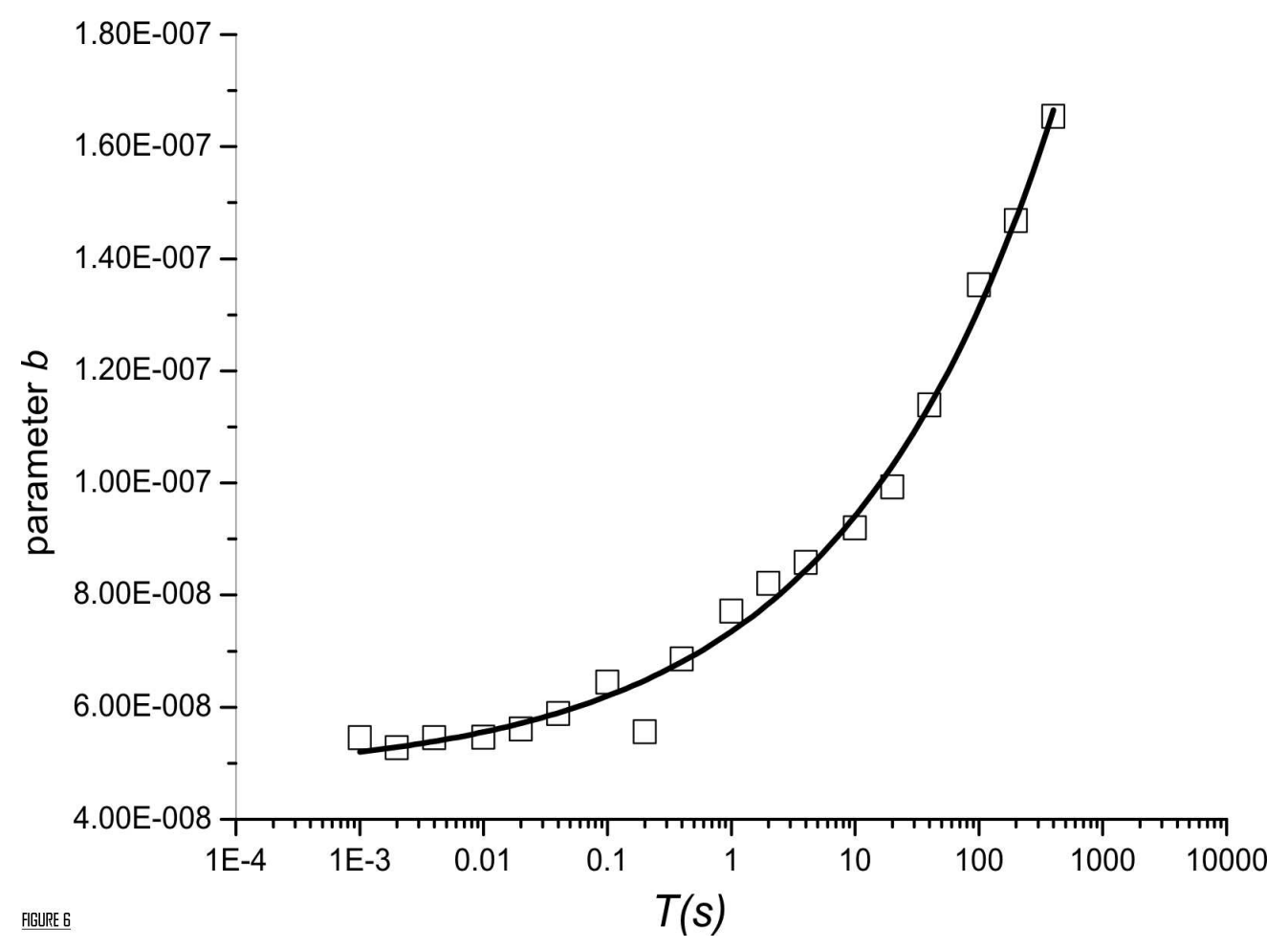

$431 \times 316 \mathrm{~mm}(96 \times 96$ DPI) 


1
2
3
4
5
6
7
8
9
10
11
12
13
14
15
16
17
18
19
20
21
22
23
24
25
26
27
28
29
30
31
32
33
34
35
36
37
38
39
40
41
42
43
40
45
49
50
51
52
53
55
50

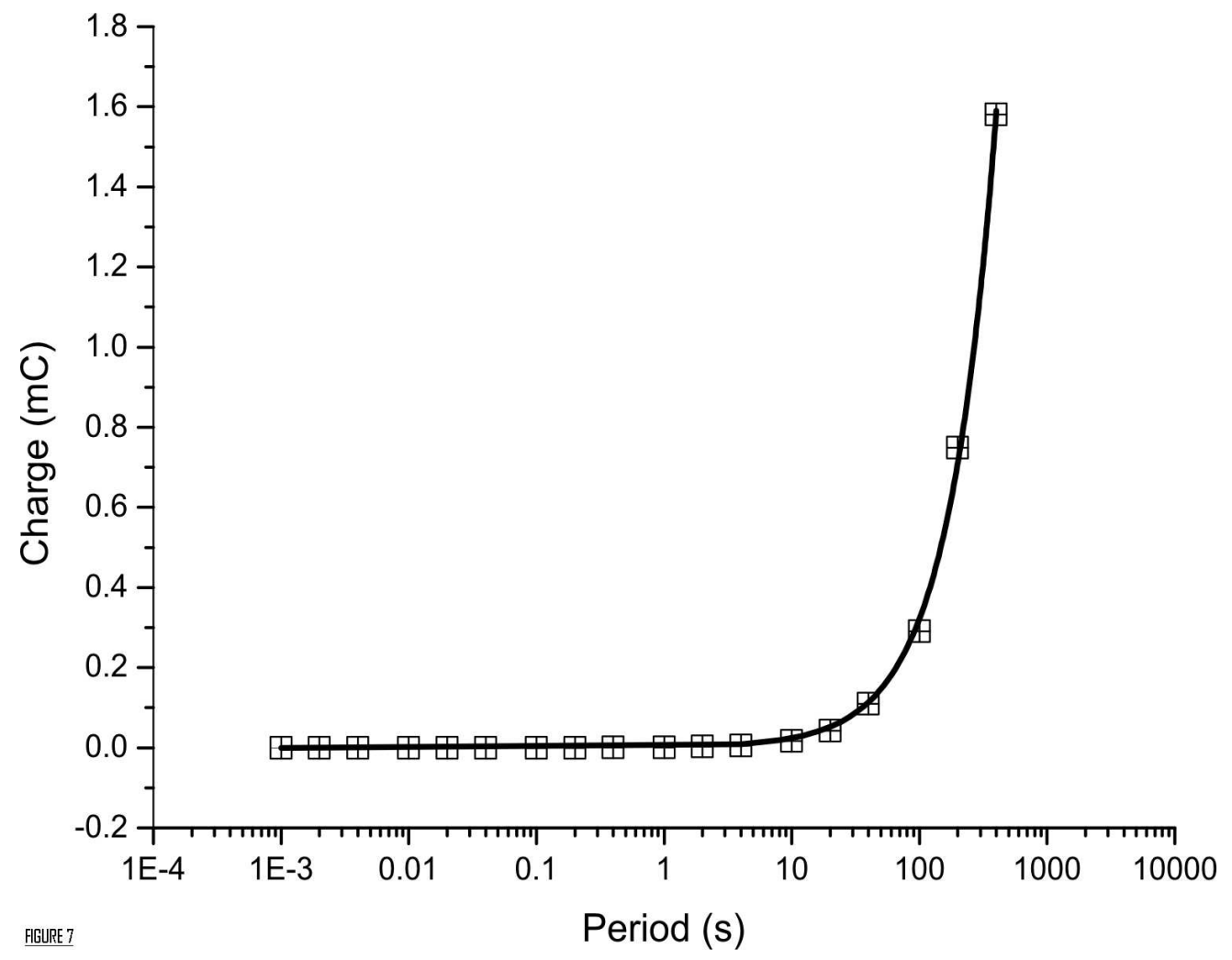

$404 \times 317 \mathrm{~mm}(96 \times 96 \mathrm{DPI})$ 

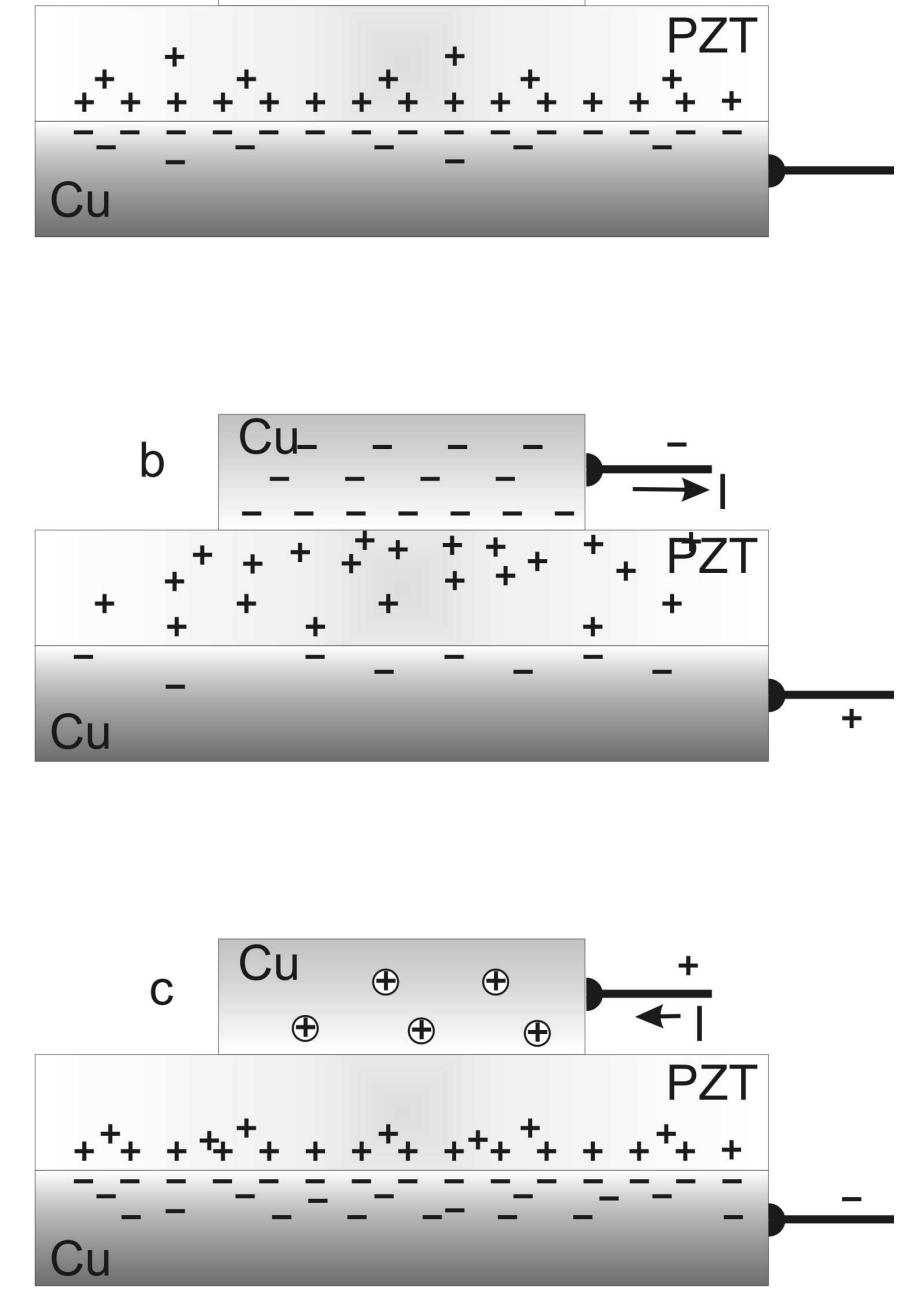

$422 \times 717 \mathrm{~mm}(96 \times 96 \mathrm{DPI})$ 


1
2
3
4
5
6
7
8
9
10
11
12
13
14
15
16
17
18
19
20
21
22
23
24
25
26
27
28
29
30
31
32
33
34
35
36
37
38
39
40
41
42
43
44
45
46
47
48
49
50
51
52
53
54
55
56
57
58
60
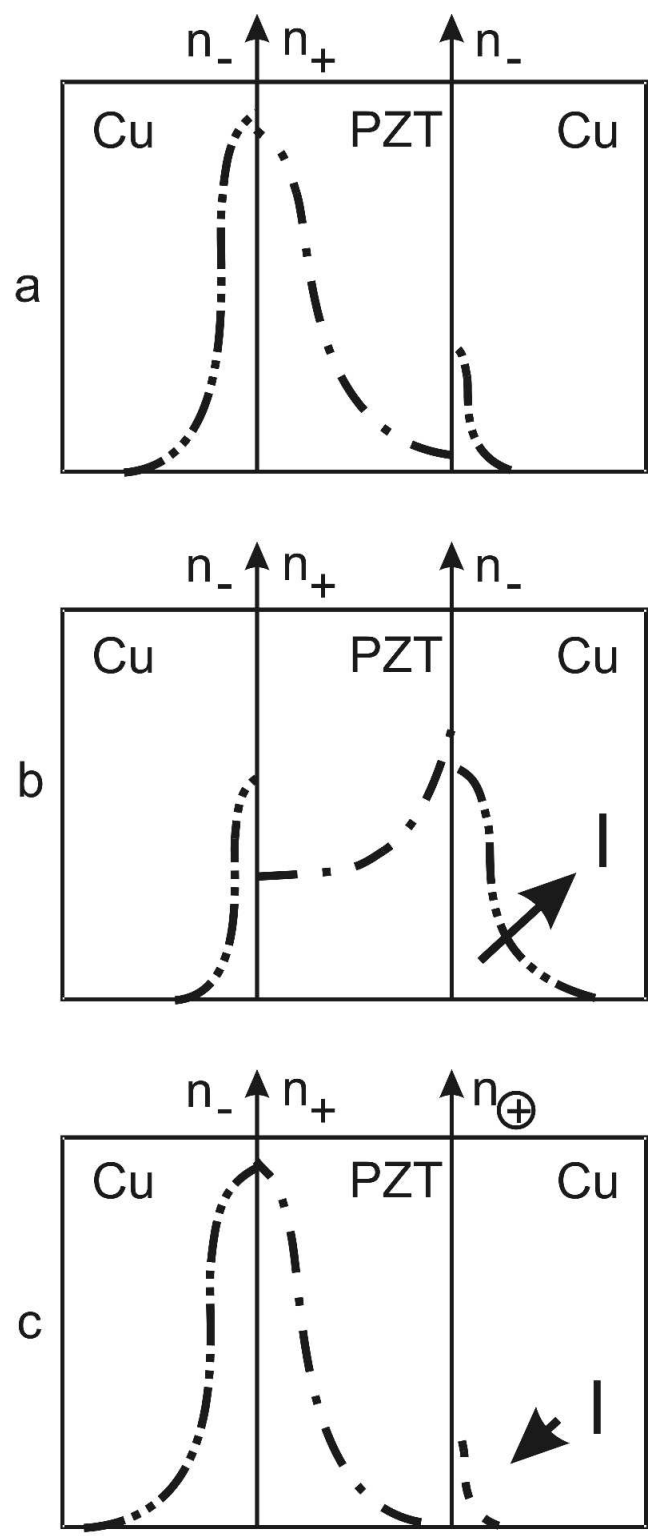